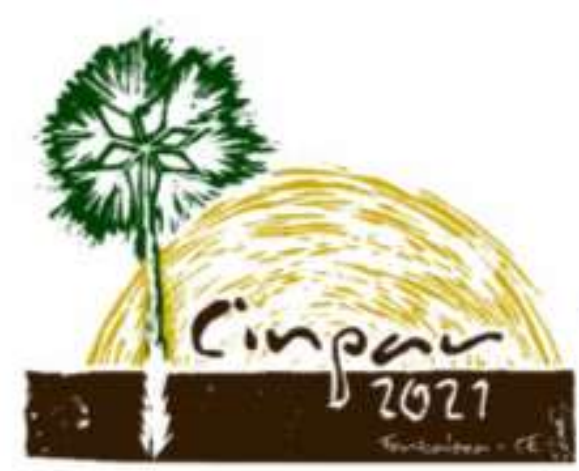

XVII Congresso Internacional sobre Patologia e Reabilitação das Construçōes

XVII Congreso Internacional sobre Patologia y Rehabilitación de las Construcciones

XVII International Conference on Pathology and Constructions Rehabilitation

FORTALEZA (Brasil), 3 a 5 de junho de 2021

https://doi.org/10.4322/CINPAR.2021.123

\title{
A Ponte de Ferro de Cachoeiro do Itapemirim
}

\section{The Iron Bridge of Cachoeiro do Itapemirim}

\author{
Eduardo, AZAMBUJA ${ }^{1}$, Hillary, Britto ${ }^{2}$, João, PANTOJA ${ }^{3}$ \\ ${ }^{1}$ UnB, Brasília, Brasil, edazambuja@globo.com \\ 2 IPOG, Goiânia, Brasil, hillarybritto@hotmail.com \\ ${ }^{3}$ UnB, Brasília, Brasil, joaocpantoja@gmail.com
}

\section{Resumo:}

Diante da importância da manutenção das edificações e da preservação de patrimônios históricos, o trabalho teve por objetivo realizar uma inspeção visual na estrutura metálica da ponte localizada na cidade de Cachoeiro de Itapemirim/ES, denominada Ponte de Ferro.

A ponte foi construída no ramal da Estrada de Ferro Leopoldina que faz a ligação entre os municípios de Cachoeiro de Itapemirim e Vitória. Fabricada pela empresa inglesa Patent Shaft \& Axletree, a obra foi inaugurada em 27 de junho de 1910 e transformou a cidade de Cachoeiro do Itapemirim em um importante centro comercial e econômico do Estado. Quando este trecho da linha ferroviária foi desativado, em 1999, a ponte passou a compor o sistema de transporte urbano de Cachoeiro do Itapemirim, utilizada na circulação de veículos leves e de pedestres.

Como metodologia de trabalho, realizou-se, inicialmente, o levantamento da geometria, dos perfis e dos materiais utilizados na treliça longitudinal da ponte e a montagem de um modelo estrutural simplificado que permitiu, por meio de uma análise qualitativa, a identificação dos pontos com solicitações críticas. A seguir foi feito um estudo de manifestações patológicas relacionadas com a utilização da Ponte de Ferro e a aplicação de uma metodologia de avaliação do grau de deterioração, denominada GDE/UnB, modificada para a inspeção visual de estruturas metálicas.

A metodologia apontou para um estado global Crítico $\left(G_{d}=157\right)$, determinando ações a serem adotadas de "Inspeção especial emergencial. Planejar intervenção imediata". Espera-se, como objetivo principal, que esse trabalho colabore para a compreensão da importância de se manter o projeto da Ponte de Ferro, por sua história, como instrumento de preservação da memória coletiva, e como um elemento importante de conexão do sistema de transporte urbano da cidade.

Palavras-chave: Construções históricas; Pontes; Estruturas metálica; Inspeção de estruturas. Heritage construcitions, Bridges; Steel structures; Inspection of structures.

\section{Introdução}

Cachoeiro de Itapemirim é uma cidade localizada no sul do estado do Espírito Santo, com uma população estimada (2019) de 208.972 habitantes e uma área territorial (2018) de 864,583 km² (IBGE). A princípio, foi criado um distrito com a designação de São Pedro de Cachoeiro de Itapemirim que, pelo Decreto Providencial no 11 de 16/7/1856, era subordinado ao município de Itapemirim. Foi elevado à categoria de Vila com a intitulação de São Pedro do Cachoeiro de Itapemirim por meio do Decreto Providencial no 11, de 23/11/1864, sendo desmembrado de Itapemirim. Em 26 de dezembro de 1889, a Vila foi elevada à condição de cidade com a denominação de Cachoeiro de Itapemirim, por meio do Decreto Estadual no 04 (IBGE, 2019). 
As décadas de 1870 e 1880 se apresentaram como um período de grande progresso de Cachoeiro de Itapemirim, foram estipuladas regras de urbanização e foi alcançada uma perceptível evolução econômica. A cultura original era a cana-de-açúcar, porém, desfrutando das diversidades de seu clima, Cachoeiro já realizava uma diversificação com o plantio de café, algodão, tabaco, banana, laranja, entre outros. Em pouco tempo o café se tornou a principal cultura da região, na qual a partir da década de 1880 já empregava 11 mil pessoas, com uma produção anual de 9 milhões de quilos, sendo a exportação realizada pelo porto de Itapemirim (MOREIRA, 2014).

\subsection{Histórico da Ponte de Ferro}

Em 1872, o deputado Basílio Carvalho Daemon apresentou um projeto para a construção de uma estrada de ferro. No entanto, somente dez anos depois o capitão Henrique Deslandes conseguiu a concessão para construir uma via férrea interligando a região de Cachoeiro de Itapemirim aos seus distritos de Alegre e Castelo, sendo os mais importantes por conta da produção cafeeira.

Por ser um empreendimento oneroso, Henrique concedeu os direitos ao Visconde de São Salvador de Matozinhos, presidente, na época, da Cia. de Navegação Espírito Santo Caravelas. Em 17 de janeiro de 1886, o desembargador Antonio Joaquim Rodrigues, Presidente da Província, bateu a estaca inicial com a presença do presidente da Câmara Gil Gourlart. O primeiro trecho, do Porto até a Estação, foi concluído em um mês e a primeira locomotiva foi montada pelo engenheiro Pedro Scherrer. Os trabalhos foram empreitados a J. Praxedes e Antonio Figueiredo, tendo a participação direta dos engenheiros Herman Schindler e Rodolfo Henrique Batista. Em oito meses concluíram 71 quilômetros de linha, interligando Cachoeiro de Itapemirim às estações de Matosinhos e Pombal (MOREIRA, 2014).

Em 16 de setembro de 1887, a Estrada de Ferro Cachoeiro, com a estação localizada na praça Jerônimo Monteiro, foi inaugurada, recebendo, também, a denominação vulgar de Estrada de Ferro Caravelas, uma vez que pertencia, na época, à The Espírito Santo and Caravellas Railway C. L. (MACIEL, 2003).

Segundo Moreira (2014), o sistema ferroviário foi de grande importância para o progresso de Cachoeiro e também de outras vilas da região. Após determinado tempo, o controle da ferrovia foi transferido ao Lóide Brasileiro e, em 1907, para a Leopoldina. Esta, por sua vez, já providenciava a ligação ferroviária da cidade de Cachoeiro de Itapemirim com o estado do Rio de Janeiro, inaugurando a estação em 25 de julho de 1903. Os trilhos chegaram ao perímetro urbano de Alegre em 1912 e à Espera Feliz em 1913 (MOREIRA, 2014).

Em 4 de junho de 1893, autorizado pelo Presidente Moniz Freire, iniciaram-se o estudo e orçamento de uma via férrea entre Cachoeiro de Itapemirim e Matilde, com entroncamento no ramal de Vitória - Rio Pardo. Em outubro do mesmo ano começou a chegar o material para o início do trecho, denominado, Estrada de Ferro Sul do Espírito Santo, vindo de navio. Em 1895, para empreitar o ramal de Cachoeiro de Itapemirim a Rio Novo e de Viana a Matilde, o estado contratou os engenheiros Henrique Reeve e João Feliciano, e o Visconde César Ferreira Pinto (MOREIRA, 2014).

Com o intuito de realizar a ligação entre as cidades de Cachoeiro de Itapemirim e de Vitória, foi construída uma ponte sobre o rio Itapemirim no ramal da E.F. Leopoldina de Cachoeiro de Itapemirim a Matilde. A obra teve início em 1908, tendo a contribuição de Álvaro Ramos com sua arte de marcenaria para definir o molde (MOREIRA, 2004).

A ponte foi fabricada pela empresa inglesa Patent Shaft \& Axletree, localizada em Wednesbury, transportada em navios a vapor (FERROVIA, s.d.) e construída sob a responsabilidade técnica do engenheiro José Bento Vidal (MOREIRA, 2004). A obra construída na cidade de Cachoeiro de Itapemirim passou a ser denominada como Ponte de Ferro (Figura 1).

Durante dois anos de trabalho fez-se a Ponte de Ferro sobre o rio Itapemirim e outras menores, dois grandes viadutos, cinco túneis e vários pontilhões (MOREIRA, 2014). No dia 27 de junho de 1910 inaugurou-se, então, a Ponte de Ferro, com a presença do Presidente da República Nilo Peçanha, do Ministro da Viação Francisco de Sá, dos generais Bento Ribeiro e Dantas Barreto, do deputado Pereira Nunes e dos senadores Bernadinho de Souza Monteiro, Moniz Freire e João Luiz Alves. Contou também com a presença da população e de demais figuras importantes, tornando-se uma grande festa cívica. No dia 18 de julho partiu o primeiro trem, iniciando, oficialmente, o tráfego da Leopoldina, de Cachoeiro de Itapemirim a Vitória (MOREIRA, 2004). 


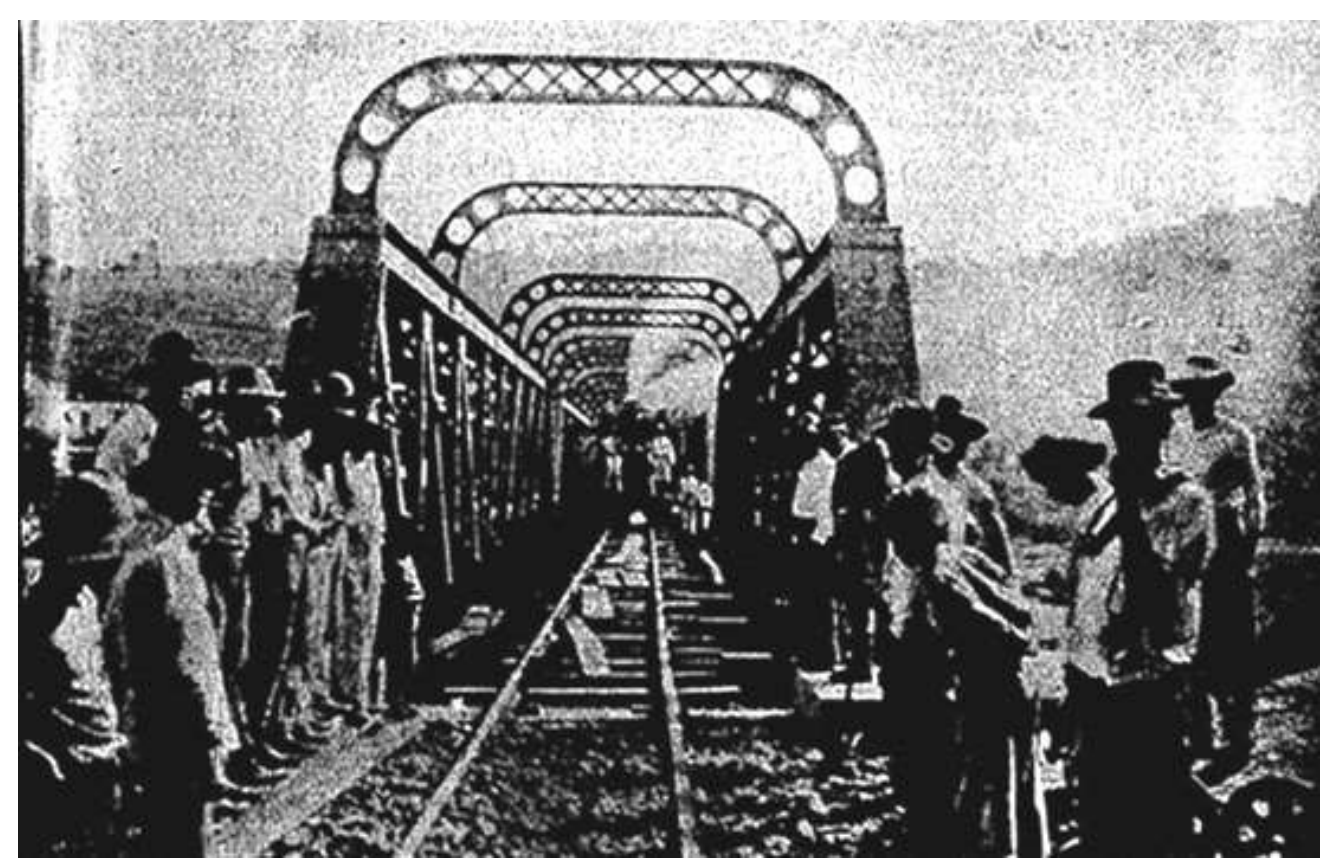

Figura 1 - Ponte de Ferro no dia em que trafegou o trem inaugural (Arquivo Público Municipal de Cultura de Cachoeiro de Itapemirim - ES (1910)

A inauguração da Ponte de Ferro transformou a cidade de Cachoeiro de Itapemirim em um importante centro comercial do Espírito Santo, sendo interligado diretamente com as capitais do estado, Vitória, e do país, na época, a cidade do Rio de Janeiro. A linha ferroviária passou a conectar a região de influência de Cachoeiro de Itapemirim com o sul do Brasil.

Acidentes nos trechos em que a linha ferroviária cortava a área urbana de Cachoeiro, contudo, também se tornaram comuns. Um dos casos mais conhecidos é o do cantor Roberto Carlos, que foi vítima do acidente quando ainda criança, precisando ter sua perna amputada (MOREIRA, 2004).

A linha ferroviária utilizou a Ponte de Ferro até o final da década de 1990, após o seu desuso, a ponte passou a servir para a passagem de veículos leves e pedestres (FERROVIA, s.d.).

Em 21 de outubro de 2003, através da Lei Municipal no 5484, ficaram reconhecidas como Patrimônio Histórico e Cultural de Cachoeiro de Itapemirim a Antiga Estação Ferroviária e a Ponte de Ferro, justificadas por compor um conjunto arquitetônico que marca a influência inglesa nos métodos construtivos em infraestrutura ferroviária e que marcou a história do desenvolvimento de transporte de cargas e de passageiros no Município e na Região Sul do Estado do Espírito Santo.

\subsection{O Modelo Estrutural da Ponte de Ferro}

A treliça plana é um modelo estrutural constituído por barras que se unem em nós, localizados nos centros geométricos das peças, para compor triângulos. Isso garante que, quando as cargas atuarem nos nós, serão desenvolvidos, predominantemente, esforços axiais de tração e compressão simples.

As barras que compõe a treliça recebem as denominações especiais de banzos, superiores e inferiores, diagonais e montantes. As treliças planas com configurações geométricas mais comuns são designadas pelos nomes dos engenheiros que as desenvolveram, como Pratt, Howe e Warren.

$\mathrm{O}$ tipo adotado na Ponte de Ferro é a treliça Pratt com montante extremo inclinado. A Ponte de Ferro possui um comprimento total de $127,2 \mathrm{~m}$, largura de $3,94 \mathrm{~m}$ e está situada a uma altura média de $7,1 \mathrm{~m}$ do rio. A sua estrutura é formada por 4 trechos iguais com 31,6 m de comprimento cada (Figura 2). 


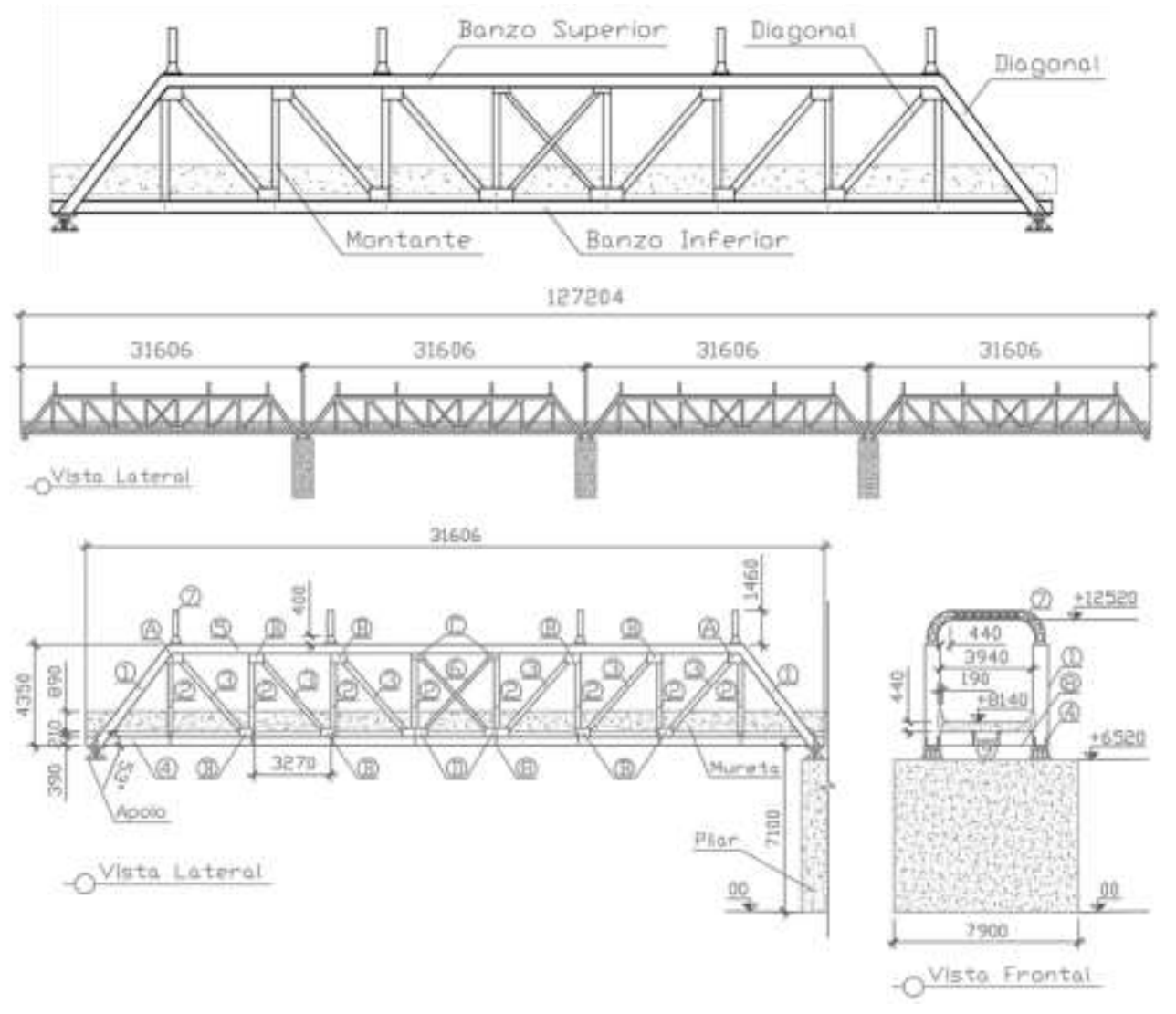

Figura 2 - Modulação da estrutura da Ponte Ferro, vista Lateral e Frontal, com cotas em "mm" (Autor, 2019)

Cada módulo da Ponte de Ferro é composto por banzos, diagonais, montantes, contraventamentos, arcos transversais, vigas longitudinais e transversais, elementos executados com perfis fabricados pela composição de chapas conectadas com rebites. A estrutura é vinculada ao pilares da ponte por aparelhos de apoio do segundo gênero, fabricados com chapas de aço, que impedem as translações verticais e horizontais do conjunto, mas liberam a rotação no plano da treliça.

As ligações entre os diversos elementos estruturais foram feitas com rebites de cabeça arredondada, conector de uso comum na fabricação de estruturas metálicas executadas na época da construção da Ponte de Ferro (Figura 3).
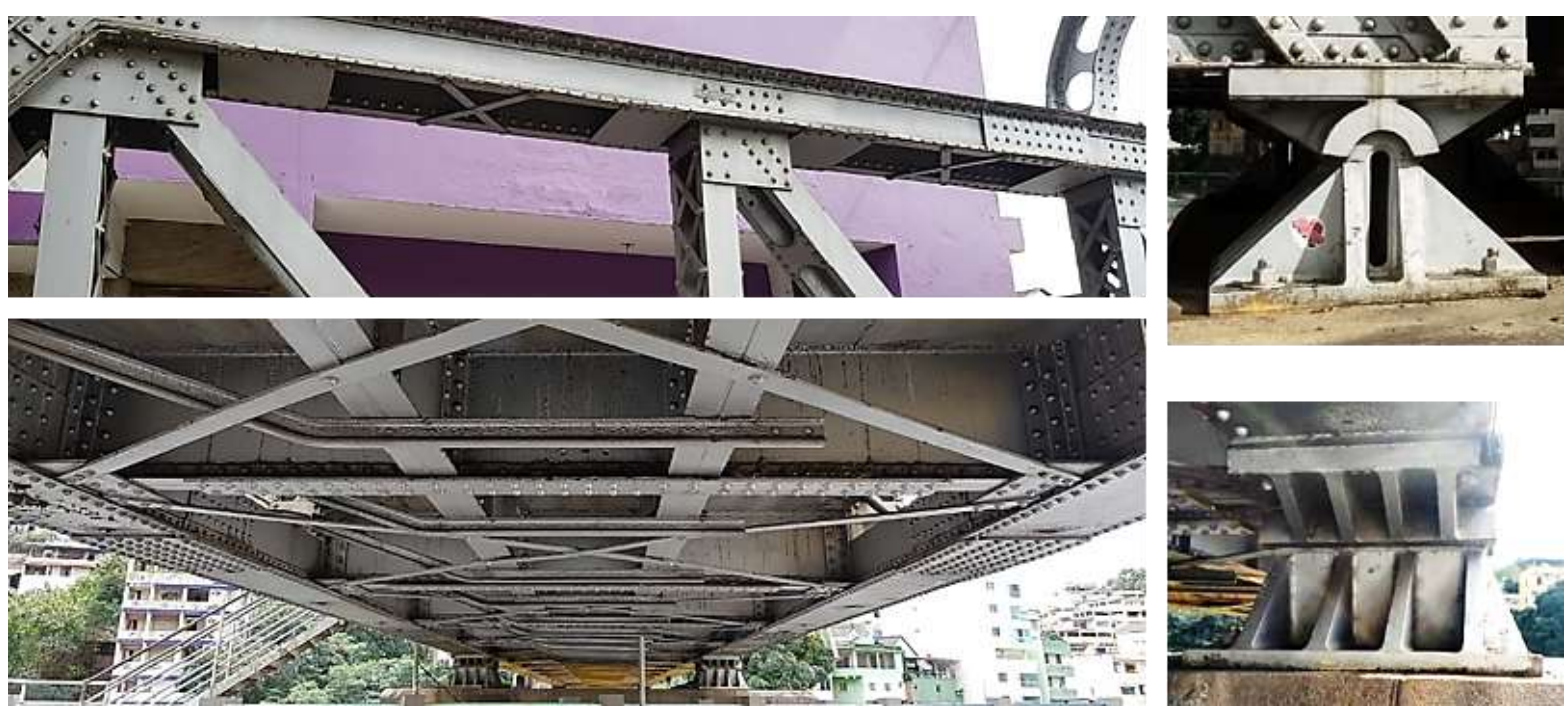

Figura 3 - Vista latera e inferior da estrutura da Ponte de Ferro e dos aparelhos de apoio (Autor, 2019) 


\subsection{A conservação de pontes metálicas}

Os principais danos que ocorrem em estruturas metálicas, em função da sua utilização e contato com o ambiente construído, alvos de inspeção deste trabalho, são: a) corrosão visível dos elementos de aço; b) falha na camada de proteção; c) falha de concordância em emendas; d) deslocamentos excessivos; e) desvio de geometria; f) falha no gabarito de furação; g) mau posicionamento de conectores.

Quando se propõe a modificação ou reabilitação de uma estrutura, verifica-se a existência da memória da sua construção, que inclui, desenhos de fabricação, de montagem e relatos da execução, coletando informações importantes que permitam avaliar a sua capacidade de atender os requisitos do projeto. Contudo, quando não há documentação disponível, torna-se necessário investigações de campo para compreender o modelo estrutural proposto, medições da geometria dos perfis utilizados, retirada de amostras para testes e obtenção das propriedades dos materiais utilizados.

Mas percebe-se, também, que conceitos estruturais bem-sucedidos em uma determinada época foram repetidos em outras obras. Isso permite que avaliações em documentação de edificações construídas em uma mesmo período, orientem as características dos materiais utilizados em obras similares.

\section{O Comportamento Estrutural da Ponte de Ferro}

\subsection{Análise qualitativa da estrutura da Ponte}

Com o auxílio do Sistema Trame, Software Educacional para Análise Linear e Não Linear de Estruturas Planas de Aço, realizou-se uma análise qualitativa de um trecho da estrutura da ponte, com o intuito de estudar o comportamento simplificado da treliça longitudinal plana utilizada na obra. Para tal, tomou-se como base o trecho da ponte que se repete ao longo de sua estrutura. Utilizou-se perfis com a geometria correspondente aos elementos da ponte, levantada no local da obra e o aço padrão ASTM A36, material com características mecânicas semelhantes ao utilizado na época. Para a análise do comportamento estrutural, considerou-se o peso próprio dos elementos e uma carga unitária vertical de 10 kN nos nós da estrutura (Figura 4).

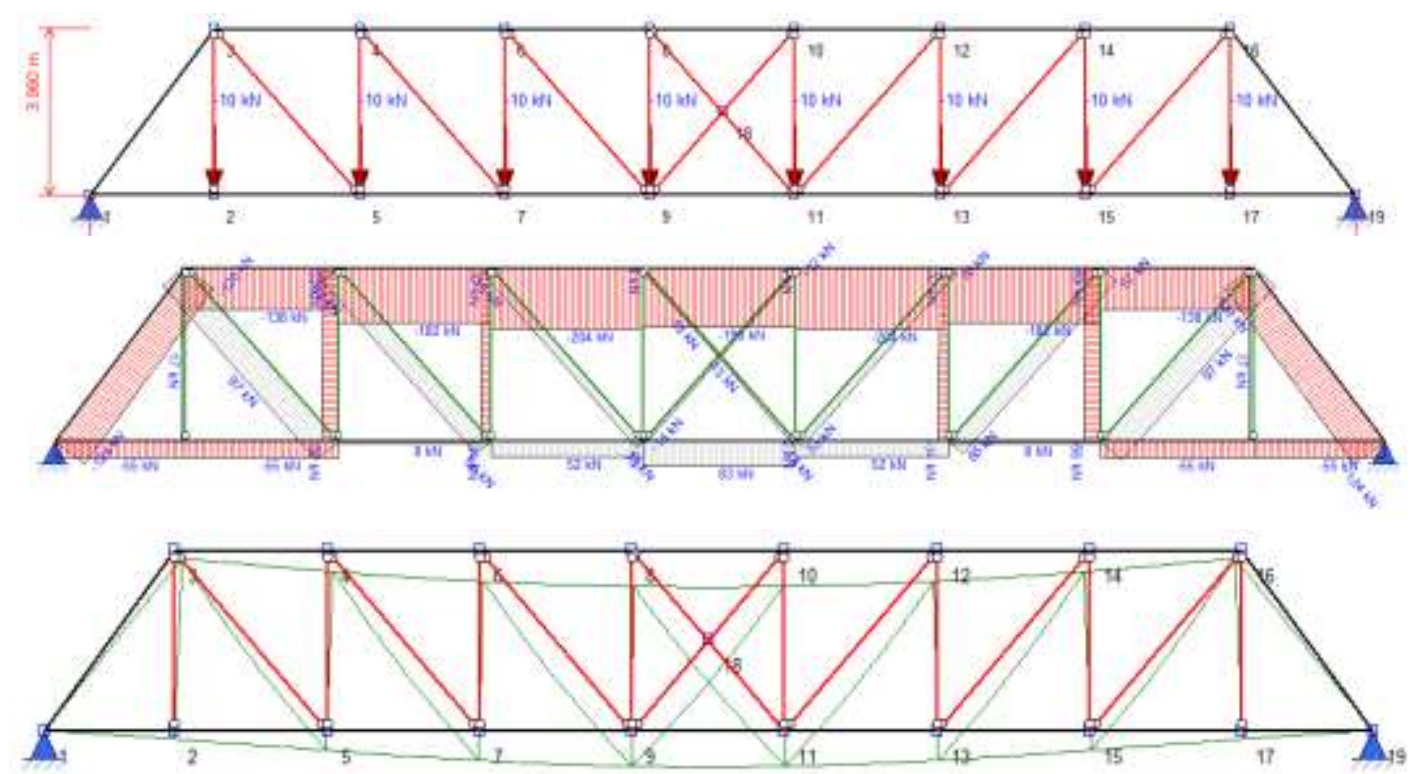

Figura 4 - Modelo estrutural da treliça da Ponte de Ferro no sistema Trame, a) cotas entre os eixos dos elementos estruturais, indicação das cargas e numeração dos nós, b) diagrama dos esforços de tração (positivos) e de compressão (negativos), c) Linha elástica da treliça (Autor, 2019).

As ações atuantes no tabuleiro da Ponte de Ferro são transferidas para as vigas transversais e delas para os nós das treliças longitudinais, fazendo com que os seus componentes fiquem submetidos, predominantemente, a esforços axiais de compressão e tração. As diagonais externas, o banzo superior e os montantes próximos aos apoios ficaram comprimidos. As diagonais internas e os elementos de contraventamento apresentaram esforços de tração (Figura 4). 
O banzo inferior encontrou-se tracionado na região central de seu vão. Pelo uso de apoio do $2 \circ$ gênero nos dois vínculos da estrutura, indeslocáveis para translações, o banzo inferior ficou submetido à esforços de compressão nos trechos extremos. Os elementos mais solicitados da treliça são as diagonais externas e o banzo superior, os quais estão sujeitos apenas ao esforço de compressão. Por serem mais críticos, esses elementos possuem maior responsabilidade estrutural, requerendo, portanto, maior atenção nos procedimentos de inspeção (Figura 4).

O nós centrais do vão da ponte, no trecho inspecionado, numerados por 8, 9, 10, 11 e 18, considerando a aplicação de um carregamento simétrico e uniforme, apresentaram, por consequência, os maiores valores de deslocamentos verticais (Figura 4).

\subsection{Grau de Deterioração da Estrutura - Metodologia GDE/UnB}

Com base em Klein (apud CASTRO, 1994), Castro (1994) desenvolveu uma metodologia denominada GDE/UnB para avaliação quantitativa do grau de deterioração de estruturas. Essa metodologia foi reformulada por Boldo (2002) e Fonseca (2007) para avaliação de importantes construções com uso de concreto armado na cidade de Brasília e adaptada por Azambuja (2012) para aplicação em estruturas metálicas (apud JUNIOR, 2019).

Na metodologia de inspeção GDE/UnB, os elementos estruturais são, primeiramente, agrupados em famílias, especificando um Fator de Relevância $\left(F_{r}\right)$ para cada uma delas, variando de 1 a 5 . Em seguida, é necessário identificar os principais danos que a estrutura pode apresentar e atribuir um Fator de Ponderação $\left(F_{p}\right)$ para cada um deles, conforme a relevância desse dano, em uma escala de 1 a 5 (sendo 5 a situação mais desfavorável). Após esta etapa, é estabelecido o Fator de Intensidade $\left(F_{i}\right)$, que quantifica o grau do dano que o elemento apresenta, variando de 0 a 4, sendo: 0 - sem lesões; 1 - lesões leves; 2 - lesões toleráveis; 3 lesões graves; e 4 - estado crítico. Dispondo dos dois fatores, é possível calcular o Grau do Dano (D) do elemento, o Grau de Deterioração do elemento $\left(G_{d e}\right)$ e o de sua família $\left(G_{d f}\right)$.

A formulação do cálculo do grau de dano apresentada por CASTRO (1994), foi baseada no modelo de evolução da corrosão de armadura proposto por TUUTTI (1982). Este modelo foi desenvolvido para descrever o mecanismo de corrosão nas armaduras de reforço do concreto, fornecendo uma possível descrição geral de como o processo de deterioração pode se desenvolver na estrutura.

O Grau de Deterioração da Estrutura $\left(G_{d}\right)$, por fim, será obtido com base no grau de deterioração de cada família de elementos inspecionados, ponderado por um Fator de Relevância Estrutural $\left(F_{r}\right)$, sendo este definido de acordo com a importância da família na deterioração da estrutura. Obtido o valor de $G_{d}$, verificase em qual nível de deterioração a estrutura é classificada e as ações que deverão ser adotadas.

\subsection{Grau de Deterioração da Estrutura - Metodologia GDE/UnB Adaptada}

A Ponte de Ferro está localizada em uma área predominantemente urbana, classificada em uma categoria de média corrosividade, do tipo C3, conforme apresentado pela ABNT NBR 8800:2008 (Figura 5).

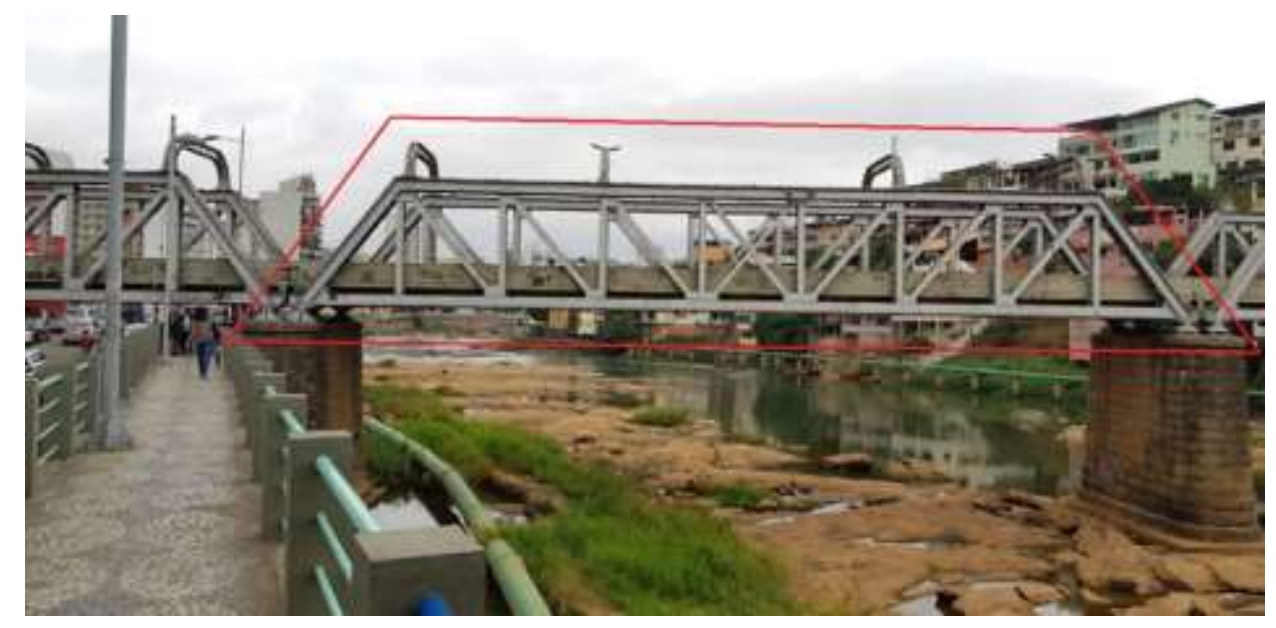

Figura 5 - Trecho inspecionado da Ponte de Ferro (AUTOR, 2019) 
De acordo com a etapa inicial da metodologia de inspeção GDE/UnB, seguindo as adaptações propostas por Azambuja (2012) para aplicação em estruturas metálicas (apud JUNIOR, 2019), seguindo o modelo de TUUTI (1982), foram criadas as seguintes famílias para a estrutura da Ponte de Ferro e adotados os respectivos fatores de relevância $\left(F_{r}\right)$ : Apoios $\left(F_{r}=5\right)$, Banzos $\left(F_{r}=5\right)$, Montantes $\left(F_{r}=3\right)$ e Diagonais $\left(F_{r}=4\right)$.

Os elementos estruturais da ponte foram inspecionados levando em consideração os seguintes danos patológicos e seus respectivos fatores de ponderação $\left(F_{p}\right)$ : corrosão visível $\left(F_{p}=5\right)$, falha de concordância em emendas $\left(F_{p}=3\right)$, falha no gabarito de furação $\left(F_{p}=3\right)$, mau posicionamento de conector $\left(F_{p}=3\right)$, desvio de geometria $\left(F_{p}=3\right)$, deslocamentos excessivos $\left(F_{p}=4\right)$ e falha na camada de proteção $\left(F_{p}=5\right)$. Por se tratar de uma ponte de grande extensão e com elevada quantidade de elementos, optou-se por realizar a inspeção visual em apenas um dos quatro trechos da Ponte de Ferro. Para complementar, inspecionou-se também os demais apoios que se encontram nos pilares centrais (Figura 5).

Os danos mais frequentes observados no trecho vistoriado estão relacionados com áreas visíveis de corrosão no aço estrutural ou com falhas na camada de proteção dos elementos. $O$ banzo inferior localizado ao lado da passarela de pedestres (BZ4) foi o elemento com maior grau de deterioração inspecionado, tendo alcançado o valor $G_{d e}$ de 163, que correspondente a um nível crítico, afetado pela corrosão verificada do material, por desvios da sua geometria original e por falhas na sua camada de proteção (Tabela 1).

Tabela 1 - Grau de Deterioração do Elemento (G_de) da família Banzos, identificado como BZ4 na estrutura da treliça longitudinal do trecho inspecionado da Ponte de Ferro (AUTOR, 2019)

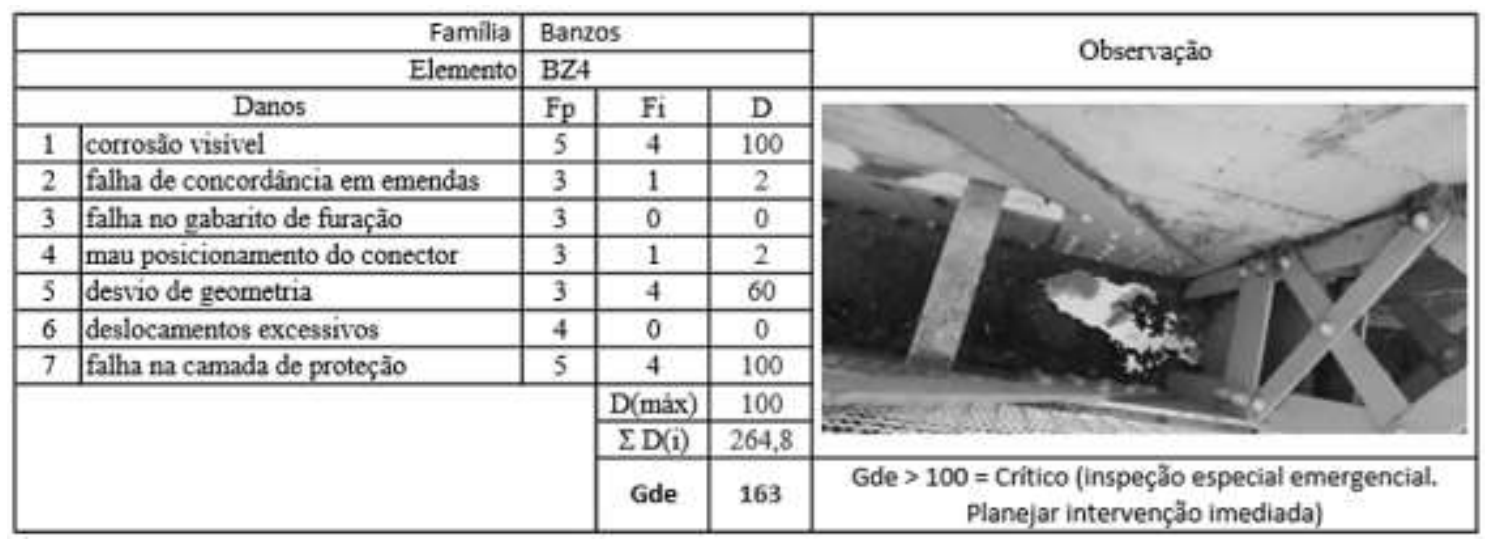

A metodologia GDE/UnB Adaptada, aplicada na Ponte de Ferro, desenvolvida de maneira simplificada na inspeção visual da estrutura metálica, apresentou Grau de Deterioração $\left(G_{d}\right)$ igual a 157 , representando um estado crítico (>100) com ações a serem adotadas de "Inspeção especial emergencial. Planejar intervenção imediata" (Tabela 2).

Tabela 2 - Resultados da metodologia GDE/UnB Adaptada, aplicada no trecho vistoriado da estrutura da Ponte de Ferro de Cachoeiro do Itapemirim (AUTOR, 2019)

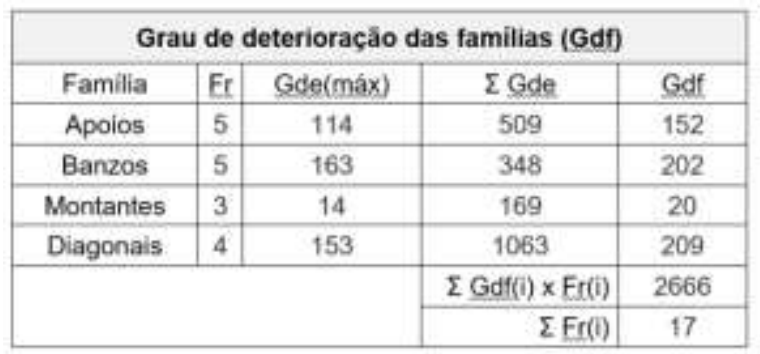

\begin{tabular}{|c|c|c|}
\hline \multicolumn{2}{|c|}{ Grau de deterioraçăo da estrutura (Gd) } \\
\hline Gd & \multicolumn{2}{|c|}{157} \\
\hline Nivel & 5 & Critico \\
\hline & \\
Recomendação: & $\begin{array}{c}\text { Inspeçăo especial emergencial. } \\
\text { Planejar intervençäo imediata. }\end{array}$ \\
\hline
\end{tabular}

A prefeitura da cidade de Cachoeiro de Itapemirim relatou não ter informações, desde a sua inauguração, de manutenções realizadas na Ponte de Ferro e a inspeção não detectou danos pontuais em elementos componentes da estrutura, provocado, por exemplo, por choques ou por usos indevidos. 


\section{Conclusão}

O levantamento do modelo estrutural da Ponte de Ferro foi relevante no desenvolvimento da inspeção da Ponte de Ferro. Por meio dele, de uma maneira qualitativa, foi possível efetuar o mapeamento dos elementos mais solicitados quanto a esforços e deslocamentos, determinando os pontos mais importantes para a aplicação da metodologia GDE/UnB.

A análise qualitativa da treliça longitudinal da ponte teve por finalidade verificar o comportamento da estrutura, demonstrar quais são as peças mais solicitadas e os nós com maiores deslocamentos. Isso permitiu focar a inspeção nos elementos estruturais mais críticos da Ponte de Ferro e consequentemente, tornar mais assertiva a inspeção visual. Considera-se essa etapa uma importante atividade no fluxo dos trabalhos de vistoria estrutural. A metodologia utilizada para avaliação das condições da estrutura da Ponte de Ferro, denominada, GDE/UnB, adaptada para a inspeção de elementos metálicos, apontou para um estado global Crítico $\left(G_{d}=157\right)$, determinando ações a serem adotadas de "Inspeção especial emergencial. Planejar intervenção imediata". O estado crítico pode acontecer por um eventual dano pontual em elementos componentes, provocado, por exemplo, por choques ou por usos indevidos, fatos que não foram observados durante a inspeção. Portanto, entende-se que o grau de deterioração detectado surgiu da aparente deficiência de manutenções preventivas na estrutura da ponte.

A Ponte de Ferro, tombada pelo Patrimônio Histórico e Cultural em 2003, faz parte da identidade cultural de Cachoeiro do Itapemirim, está entre as construções mais antigas do município, representa um marco importante na formação do sociedade. E, por sua funcionalidade, a ponte ainda é um importante elemento de conexão urbana, utilizada no fluxo de veículos leves, bicicletas e pedestres, interligando o centro da cidade com o bairro dos Ferroviários, torna-se importante o investimento na sua manutenção.

Assim, propõe-se, de maneira imediata, conforme resultado do estudo, a inspeção detalhada de toda a extensão da estrutura da ponte para a obtenção de resultados mais acurados. Sugere-se ainda, após a recuperação de suas condições de projeto, um trabalho contínuo de monitoramento da Ponte de Ferro, atrelado a um plano adequado de manutenções preventivas.

\section{Referências Bibliográficas}

Boldo, P. 2002. Avaliação quantitativa de estruturas de concreto armado de edificações no âmbito do Exército Brasileiro. Dissertação (Mestrado). Brasília: Universidade de Brasília. Departamento de Engenharia Civil, 2002.

Castro, E.K., Desenvolvimento de Metodologia para Manutenção de Estruturas de Concreto Armado. Dissertação (Mestrado em Estruturas), Departamento de Engenharia Civil. Universidade de Brasília, Brasília, DF, 1994.

Ferrovia, Pedro. Linha do trem que atravessava a ponte de ferro até a década de 90. [s.d]. 1 fotografia, p\&b. (Coleção Acervo Iconográfico do Museu Ferroviário Domingos Lage, Cachoeiro de Itapemirim, ES).

Fonseca, R. P. 2007. A estrutura do Instituto Central de Ciências: Aspectos históricos, científicos e tecnológicos de projeto, execução, intervenção e propostas de manutenção. Dissertação (Mestrado). Brasília: Universidade de Brasília. Departamento de Engenharia Civil, 2007.

IBGE - INSTITUTO BRASILEIRO DE GEOGRAFIA E ESTATÍSTICA. Biblioteca. Disponível em: <https://biblioteca.ibge.gov.br/biblioteca-catalogo?id=31242\&view=detalhes>. Acesso em: 31 jul. 2019.

Junior, Arlindo Tavares de Souza. 2019. Avaliação da degradação de torres de sustentação estruturadas em aço: estudo de caso na região amazônica. Belém : Universidade Federal do Pará. Programa de Pós Graduação em Engenharia Civil (PPGEC)., 2019.

MacieL, Manoel Gonçalves. Voltando ao Cachoeiro Antigo. 1 ed. Cachoeiro de Itapemirim: GRACAL, 2003. v. 2.

Moreira, Evandro. Cachoeiro: Uma História de Lutas. Cachoeiro de Itapemirim: Editoração Eletrônica, 2004. v. 1.

Parker, Bev. A History of Wednesbury. [s.d.]. Disponível em: <http://www.historywebsite.co.uk/articles/Wednesbury/PatentShaft1.htm>. Acesso em: 05 set. 2019.

Tuutti, Kyösti. Corrosion Steel in Concrete. Stockholm: Sewdish Cement and Concrete Research Institute, 1982.

Vidal, José Bento. Ponte de Ferro no dia em que trafegou o trem inaugural. 1910. 1 fotografia, p\&b. (Arquivo Público Municipal de Cultura de Cachoeiro de Itapemirim - ES). 